\title{
Modification of optical properties of seawater exposed to oil contaminants based on excitation-emission spectra
}

\author{
E. Baszanowska \\ eba@am.gdynia.pl
}

Z. Otremba
Gdynia Maritime University, Physics Department, Gdynia, 81225, Poland

Gdynia Maritime University, Physics Department, Gdynia, 81225, Poland

The optical behaviour of seawater exposed to a residual amount of oil pollution is presented and a comparison of the fluorescence spectra of oil dissolved in both n-hexane and seawater is discussed based on excitation-emission spectra.

Crude oil extracted from the southern part of the Baltic Sea was used to characterise petroleum properties after contact with seawater. The wavelength-independent fluorescence maximum for natural seawater and seawater artificially polluted with oil were determined. Moreover, the specific excitation-emission peaks for natural seawater and polluted water were analysed to identify the natural organic matter composition. It was found that fluorescence spectra identification is a promising method to detect even an extremely low concentration of petroleum residues directly in the seawater. In addition, alien substances disturbing the fluorescence signatures of natural organic substances in a marine environment is also discussed.

[DOI: http://dx.doi.org/10.2971/jeos.2015.15047]

Keywords: Optics of oil, fluorescence spectroscopy, excitation-emission spectra, oil pollution, seawater

\section{INTRODUCTION}

Optical methods, including those based on various kinds of electromagnetic radiation, have preferential position in oil pollution detection in natural waters, because only light can penetrate the water comparatively deeply. When light interacts with the water constituents, the spectral and directional distribution of the light radiance is modified [1].

Petroleum substances absorb light in the short wavelengths of the visual part of the spectrum (VIS) [2]-[4] and if they are excited by ultraviolet light (UV) they emit light in UV and VIS [5]-[7]. However, if an in-water or above-water optical detector of petroleum substances (oil) is employed, integrated information on the spectroscopic features of an oil and the natural constituents of the water should be known.

Although chromatographic methods are preferred for studying the complex structure of petroleum products, fluorescence spectroscopy seems to be the most efficient tool for low oil concentrations. Fluorescence spectroscopy allows measurements based on various methods, such as fluorescence spectroscopy for single excitation wavelength (SWEx), single emission wavelength (SWEm), excitation-emission spectroscopy (EEMs) or synchronous fluorescence spectroscopy (SFS) [8][13] and has been used to study petroleum products [14], inter alia, in marine environments [15].

However, an important point is the fact that oil disturbs the shape of the fluorescence spectra obtained for natural organic constituents of seawater. In the case of a low oil concentration it is difficult to separate the fluorescence of the natural seawater constituents from fluorescence excited by hydrocarbon compounds originating from oil pollution. For a description of the individual constituents of seawater, numerous techniques based on fluorescence spectroscopy have been developed to detect and identify these substances as well as to monitor the long-time concentration changes. Coble et al. repeatedly described the absorption spectrum as well as the fluorescence spectra for seawater based on EEMs [16]-[18]. The position of specific points described as the typical fluorescence peaks for CDOM (colourd dissolved organic matter) varies for inshore or offshore waters or rivers as well as river estuaries. The season also plays a significant role $[19,20]$. However, in order to expand knowledge about the natural marine environment, it is necessary to study oil pollutants potentially found in a marine environment, especially along intensive navigation routes. Studies on petroleum substances indicate that the fluorescence of oil is partially covered in an area where chlorophyll or CDOM strongly absorbs light radiation [11], [21]-[23]. Therefore, both optical properties of natural seawater constituents as well as oil substances should be included in operational models to track CDOM or marine phytoplankton in marine waters [24] and to construct models for other marine optical parameters [25]-[27] or detect the presence of oil substances [21] and build remote sensing products. Furthermore, such data on seawater components would allow remote sensing measurements based on optical methods to be applied to satellite measurements [17].

This paper reports on studies of the differences between excitation-emission spectra (EEMs) for oil dissolved in nhexane and oil dissolved in seawater after seawater exposure to crude oil as well as on the mutual shadowing of 
fluorescence signatures of natural and alien constituents of the seawater. The comparison of EEMs for the wavelengthindependent fluorescence maximum - the specific peak position (of seawater samples and seawater samples contaminated by crude oil for different oil concentrations) is discussed in relation to the natural seawater constituents as way to identify oil pollution in natural seawater. The results described by the specific fluorescence signatures of crude oil complement the optical properties of oils in a sea environment.

\section{MATERIAL AND METHOD}

\subsection{Material}

Petrobaltic-type crude oil was used to prepare samples containing various amounts of oil. Two samples containing crude oil were prepared: crude oil dissolved in n-hexane and a small crude oil droplet was added to seawater.

\subsubsection{Oil in n-hexane samples}

In order to prepare oil samples, Petrobaltic crude oil extracted from the Baltic Sea in the Polish Exclusive Economic Zone was used. As a solvent, n-hexane (Merck, for analysis, 96.0\% purity) was applied. Next, the base (stock solution) samples for crude oil in n-hexane was prepared. Based on the dilution method, three individual concentrations of oil samples were prepared and are presented in Table 1. A detailed description of the sample preparation procedure has been previously described by the authors [11].

\begin{tabular}{c|c}
\hline \multicolumn{2}{c}{ PETROBALTIC $(\mathrm{P})$} \\
\hline Sample & $\mathrm{c}[\mathrm{ppm}]$ \\
\hline P1 & 20 \\
P2 & 50 \\
P3 & 200 \\
\hline
\end{tabular}

TABLE 1 Petrobaltic in n-hexane [11].

\subsubsection{Seawater sample collection}

Seawater samples were taken from two sites in the vicinity of Gdynia (Gulf of Gdansk in the Southern Baltic Sea). Seawater samples from both sites Gdynia-Orlowo walking pier (in brief ORLOWO) and Gdynia-Port (PORT) were collected from a $1 \mathrm{~m}$ depth into 11 glass bottles, at two times on June 2015 . These sampling stations have a different character due to the fact that PORT station is located in an area of high maritime shipping traffic, while the ORLOWO station is located in the vicinity of Orlowo Cliff - a nature conservation area.

\subsubsection{Oil-in-water samples}

Small amounts of oil placed on a slice of aluminium foil were weighted and inserted into a seawater sample (Figure 1) to reach the desired oil-to-water ratio (Table 2). Seawater samples were polluted by oil and next EEMs were measured in the day of seawater sampling.

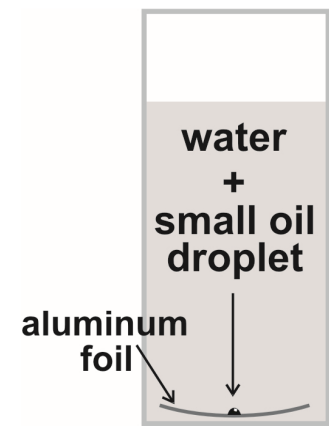

FIG. 1 The preparation method for a seawater sample contaminated by a small amount of oil.

\begin{tabular}{cc|c}
\hline \multicolumn{3}{c}{ PETROBALTIC in seawater (Ps) } \\
\hline \multicolumn{2}{c}{ Sample } & c [ppm] \\
\hline Po1 & Pp1 & 20 \\
Po2 & Pp2 & 50 \\
Po3 & Pp3 & 200 \\
\hline
\end{tabular}

TABLE 2 Petrobaltic (P) crude oil amount applied to seawater samples from GdyniaOrlowo pier (o), Gdynia Port (p).

\subsection{Measurement and apparatus}

\subsubsection{0il in n-hexane samples}

EEM spectra of oil in n-hexane samples were obtained with an Aqualog Horiba spectrofluorometer. The EEMs for all solutions were measured in a $1 \times 1 \mathrm{~cm}$ quartz cuvette. The following measurement parameters were applied to EEM spectra measurements for crude oil samples dissolved in n-hexane: excitation wavelength from $240 \mathrm{~nm}$ to $600 \mathrm{~nm}$ with a $5 \mathrm{~nm}$ sampling interval, emission wavelength from $260 \mathrm{~nm}$ to 600 $\mathrm{nm}$ with a $1.623 \mathrm{~nm}$ sampling interval, a $5 \mathrm{~nm}$ excitation slit, a $5 \mathrm{~nm}$ emission slit and a $1 \mathrm{~s}$ integration time. The spectrofluorometer software package allows automatic removal of Raman and Rayleigh scattering [28] to yield a digital matrix of excitation-emission spectra.

\subsubsection{Water samples contaminated by oil}

EEM spectra of Petrobaltic crude oil samples dissolved (after seawater was exposed to crude oil) in seawater were measured using a Hitachi F-7000 FL spectrofluorometer. EEMs for the solvent - pure seawater and for each concentration of oil in seawater were measured in a $1 \times 1 \mathrm{~cm}$ quartz cuvette. The following measurement parameters were applied to EEM measurements for pure seawater and crude oil seawater samples: excitation wavelength from $200 \mathrm{~nm}$ to $480 \mathrm{~nm}$ with excitation sampling interval $5 \mathrm{~nm}$, emission wavelength from $260 \mathrm{~nm}$ to $700 \mathrm{~nm}$ with emission sampling interval $5 \mathrm{~nm}$, excitation slit $10 \mathrm{~nm}$, emission slit $10 \mathrm{~nm}$, integration time $0.5 \mathrm{~s}$ and photomultiplier tube voltage $400 \mathrm{~V}$.

First, the EEM spectra for solvent - pure seawater at a stabilised temperature of $20^{\circ} \mathrm{C}$ were determined. Next, the EEM spectra of seawater exposed to Petrobaltic crude oil for four particular oil concentrations were measured, also at a stabilised temperature of $20^{\circ} \mathrm{C}$. Further, to obtain the real EEMs of petroleum substances diluted in seawater, the data of sea- 

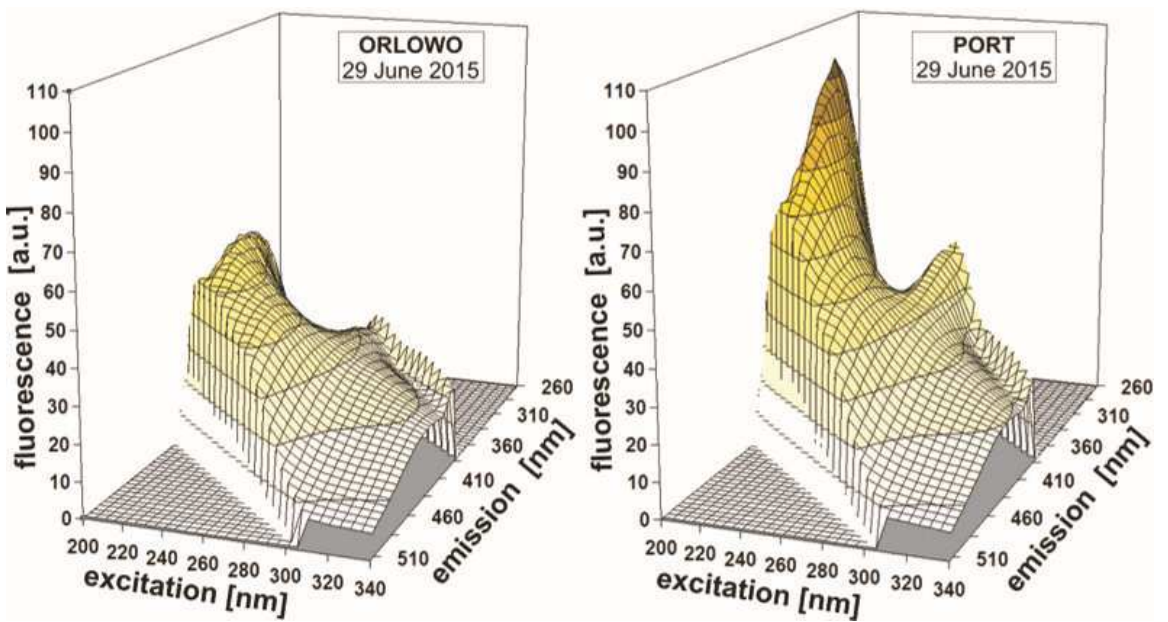

FIG. 2 EEM spectra of seawater samples from the Southern Baltic Sea Gdynia-Orlowo walking pier (ORLOWO) and Gdynia-Port (PORT).

water contaminated by oil were corrected by subtracting the spectra of uncontaminated seawater.

\section{RESULTS AND DISCUSSION}

\subsection{Manifestation of oil in Excitation-Emission Spectra}

\subsubsection{Seawater sample analysis}

The Excitation-Emission spectra (EEMs) for seawater samples (not yet artificially contaminated by oil) were determined on the days of sampling. Figure 2 presents non-normalized EEMs of seawater samples from two considered stations ("PORT" and "ORLOWO") in a three-dimensional plane. The EEMs in Figure 2 clearly indicate that the intensity of fluorescence for the "PORT" sample is twice as much as the "ORLOWO" sample. However, when the EEM spectra were expressed as normalized contour plots in a two dimensional plane, distinct differences among seawater samples from two stations can be seen. Figure 3 presents the normalized EEMs of seawater samples from both stations: Gdynia-Port - PORT (left) and the Gdynia-Orlowo walking pier - ORLOWO (right) both for the two sampling dates. In Figure 3, the shape of the EEM spectra shows intense fluorescence. For the "PORT" seawater sample, intense fluorescence is observed at an excitation wavelength from $200 \mathrm{~nm}$ to $260 \mathrm{~nm}$ (centred at $225 \mathrm{~nm}$ ) corresponding to an emission wavelength from $300 \mathrm{~nm}$ to $400 \mathrm{~nm}$ (centred at 355) and a second slight intense fluorescence is observed at an excitation wavelength from $255 \mathrm{~nm}$ to $280 \mathrm{~nm}$ (centred at $275 \mathrm{~nm}$ ) corresponding to an emission wavelength from 320 $\mathrm{nm}$ to $350 \mathrm{~nm}$ (centred at $340 \mathrm{~nm}$ ) while for ORLOWO seawater sample, an intense fluorescence is observed only at an excitation wavelength from $200 \mathrm{~nm}$ to $280 \mathrm{~nm}$ (centred at 225 $\mathrm{nm}$ ) corresponding to an emission wavelength from $300 \mathrm{~nm}$ to $460 \mathrm{~nm}$ (centred at $390 \mathrm{~nm}$ ). The above peaks detected in the shape of EEMs in Figure 3 can be described by the specific wavelengths: excitation maximum and emission maxi- mum as the peak position of wavelength-independent fluorescence maximum, written as $\mathrm{Ex}_{\max } / \mathrm{Em}_{\max }$ (EEMs peak). The wavelength-independent fluorescence maxima for seawater samples from both sampling stations indicated in Figure 3 and listed in Table 3 (above described peaks were numbered as Peak 1, Peak 2 for each station). The data allow to consider the stations based on detected peaks take into account the different detected peaks for two stations (see Table 3). However, detected individual peaks for two different stations overlap while some of them are individual and typical for such kind of station. Moreover, for the entire Excitation-Emission natural seawater constituent spectrum described by several peaks $[17,29]$ presented in Table 4, the detected peaks for both two stations (Table 3 ) correspond to some of the natural seawater constituents listed in Table 4 . The major fluorescent peak described by $E_{\max } / \mathrm{Em}_{\max }=225 / 340-390 \mathrm{~nm}($ Peak 1) determined for each sample and the second fluorescent peak described by $\mathrm{Ex}_{\max } / \mathrm{Em}_{\max }=275-278 / 340-355$ nm $($ Peak 2) are well-linked to the tryptophan-like seawater component (see Table 4).

\subsubsection{Seawater samples contaminated by oil}

The sample Excitation-Emission spectra of Petrobaltic crude oil dissolved in seawater from ORLOWO station at the end of spring in 3D-plane (left) and in 2D-plane (right) for different oil concentrations (20 ppm, 50 ppm and 200 ppm - such amounts of oil could possibly be found in seawater due to intensive marine fleet exploitation) are presented in Figure 4. An evolution of the EEM spectra of oils dissolved in seawater is seen in this figure when the oil concentration changes and can be described by the specific peaks to determine the wavelength-independent fluorescence maxima. Two specific peaks can be determined when a low oil concentration $20 \mathrm{ppm}$ is considered: the major fluorescent peak position described by $\mathrm{Ex}_{\max } / \mathrm{Em}_{\max }=225 / 340 \mathrm{~nm}$ and the second peak position described by $\mathrm{Ex}_{\max } / \mathrm{Em}_{\max }=$ 275/335 nm. Furthermore, when the highest oil concentration 

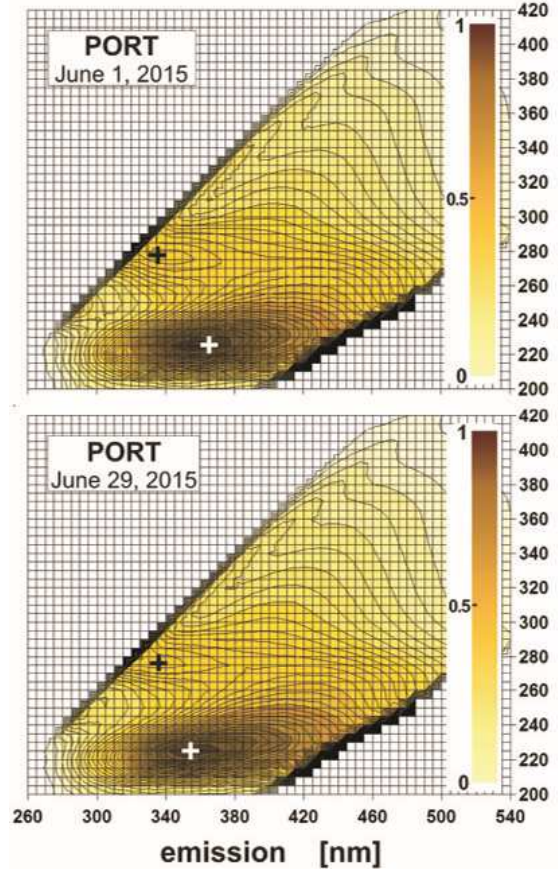

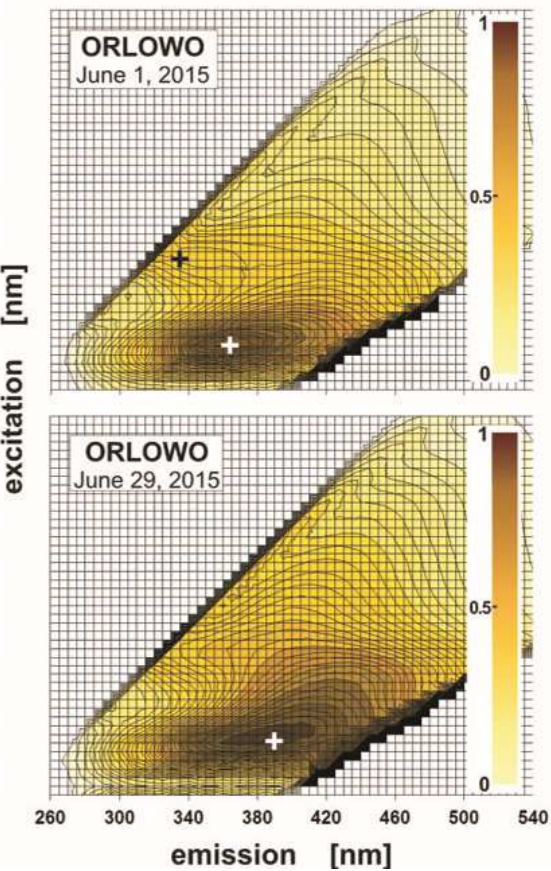

FIG. 3 Normalized excitation-emission fluorescence spectra (EEMs) of seawater samples from the Southern Baltic Sea Gdynia-Orlowo walking pier (ORLOw0) and Gdynia-Port (PORT). Crosses indicate clearly formed maxima (listed in Table 3).

\begin{tabular}{c|cc|cc}
\hline & \multicolumn{3}{c}{$\mathrm{Ex}_{\max }[\mathrm{nm}] / \mathrm{Em}_{\max }[\mathrm{nm}]$} & \\
& Peak 1 & Peak 2 & Peak 1 & Peak 2 \\
\hline ORLOWO & $225 / 365$ & $275 / 335$ & $230 / 390$ & unformed \\
PORT & $225 / 355$ & $275 / 335$ & $225 / 355$ & $278 / 338$ \\
\hline
\end{tabular}

TABLE 3 Major fluorescent peaks of seawater with their wavelength-independent maxima for ORLOWO and PORT stations.

\begin{tabular}{l|l}
\hline seawater component & $\mathrm{Ex}_{\max }[\mathrm{nm}] / \mathrm{Em}_{\max }[\mathrm{nm}]$ \\
\hline tyrosine-like & $275 / 305$ \\
tryptophan-like & $225 / 340-390,275 / 340$ \\
UVC-humic-like & $260 / 400-460$ \\
UVA-humic-like & $320-360 / 420-460$ \\
marine humic-like & $290-310 / 370-410$ \\
pigment-like & $398 / 660$ \\
\hline
\end{tabular}

TABLE 4 Major fluorescent components of seawater with their wavelength-independent maxima $[17,29]$.

(200 ppm) is considered, the third peak position described by $\operatorname{Ex}_{\max } / \mathrm{Em}_{\max }=218 / 300 \mathrm{~nm}$ can be determined. At the lower concentration this peak is not sufficiently pronounced to form an actual peak. Moreover, in Figure 4 it is clearly visible that when the oil concentration increases, the fluorescence of the major fluorescent peak described by $\mathrm{Ex}_{\max } / \mathrm{Em}_{\max }=225 / 340 \mathrm{~nm}$ intensively increases whereas other peaks grow insensibly. The wavelength-independent fluorescence maxima described by the maximum excitation corresponds to the maximum emission wavelength for Petrobaltic crude oil dissolved in seawater for two sampling dates in June and the average values are presented in Table 5. Moreover, when the determined peak positions of oil in seawater were compared to the peaks detected for natural seawater from two considered stations (Table 3), caused by oil deterioration of recognisability of fluorescence signatures of natural seawater constituents is noticeable - spectrum derived from natural ingredients sinks in the spectrum derived from the oil. This shows that the oil fluorescence peaks in seawater overlap the fluorescence peaks of natural seawater constituents presented in Figures 2 and 3. Moreover, for a low oil amount, the fluorescence of natural seawater constituents can be detected as the amount of oil increases and the fluorescence of natural seawater constituent is disturbed and dominated by the fluorescence of oil.

\begin{tabular}{c|c|c|c}
\hline & \multicolumn{3}{|c}{ Ex $_{\max }[\mathrm{nm}] / \mathrm{Em}_{\max }[\mathrm{nm}]$} \\
& Peak 1 & Peak 2 & Peak 3 \\
\hline Po1 & $225 / 340$ & $275 / 335$ & - \\
Po2 & $225 / 340$ & $275 / 335$ & - \\
Po3 & $225 / 340$ & $275 / 335$ & $218 / 300$ \\
\hline
\end{tabular}

TABLE 5 Major fluorescent peaks of Petrobaltic crude oil dissolved in seawater with their wavelength-independent maxima for the ORLOWO average for two times on the 1st and 29th of June.

It is also worth noting that for the oil concentration range studied (from 20 ppm to 200 ppm), there is a significant difference in the shape of EEMs of natural seawater (see Figure 3) observed in relation to the EEMs of seawater contaminated by oil (Figure 4). However, to identify oil pollutants in a given seawater it is necessary to consider only EEMs caused by oil component fluorescence. This is clearly seen in Figure 5 due to the shape of EEMs of oils dissolved in seawater (the upper row in Figure 5) being different in relation to the EEMs caused by the oil component and natural seawater constituents (signed "total" in the lower row in Figure 5). 


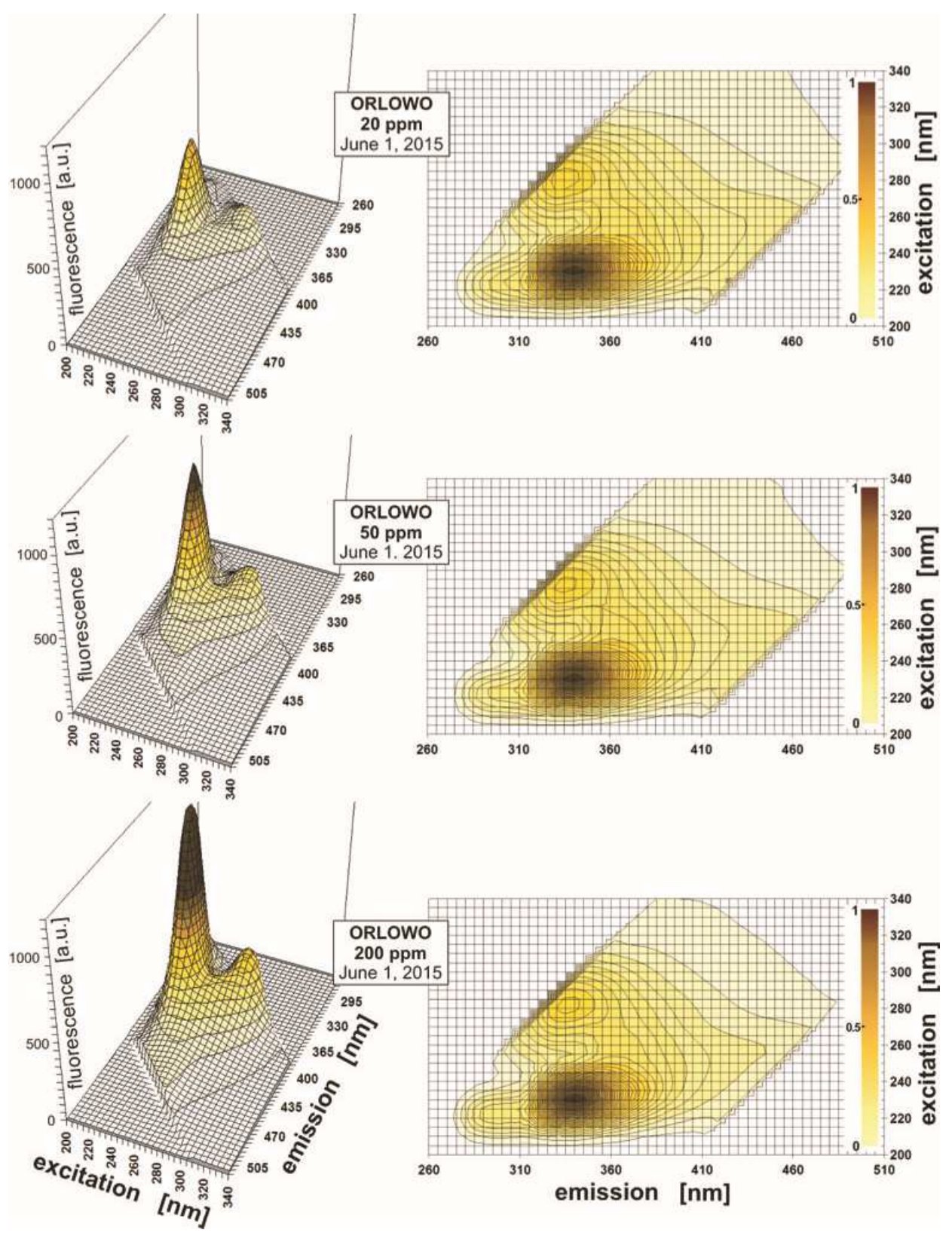

FIG. 4 Excitation-emission fluorescence spectra of Petrobaltic crude oil dissolved in seawater from the 0RLOW0 station for oil concentrations of 20 ppm, 50 ppm and 200 ppm, respectively (note that intensity of fluorescence in for unpolluted seawater shown in Figure 3 is several times lower).

\subsection{Identification of oil indices in EEMs}

Since the goal is to use the EEM spectra for petroleum substance identification in seawater, it is necessary to know the real spectrum of oil. The EEM spectra of Petrobaltic crude oil dissolved in n-hexane for several oil concentrations were determined previously by the authors [11]. In Figure 6, normalized EEMs of crude oil dissolved in n-hexane for oil concentrations of $20 \mathrm{ppm}$ and $50 \mathrm{ppm}$ (the right column in Figure 6) in relation to the EEMs of oil dissolved in seawater (the left column in Figure 6) are presented. In Figure 6, it is clearly visible that the EEMs of crude oil have specific peak positions: the major peak $\mathrm{Ex}_{\max } / \mathrm{Em}_{\max }=240 / 350 \mathrm{~nm}$ for both 20 and $50 \mathrm{ppm}$ and the second peak for an oil concentration of 20 ppm Ex $\max _{\max } / \mathrm{Em}_{\max }=265 / 320 \mathrm{~nm}$. Taking into account the above-mentioned in relation to the EEMs of oil substances dissolved in seawater, one can notice that the major peak detected for oil in seawater described by $\mathrm{Ex}_{\max } / \mathrm{Em}_{\max }=225 / 340 \mathrm{~nm}$ partially covers a major peak for oil dissolved in n-hexane. Moreover, the second peak determined for oil dissolved in seawater for an oil concentration of $20 \mathrm{ppm} \mathrm{Ex}$ max $/ \mathrm{Em}_{\max }=275 / 335 \mathrm{~nm}$ in relation to the oil dissolved in $\mathrm{n}$-hexane is shifted to the longer emission wavelengths and partially covers the peak for crude oil dissolved in n-hexane (tests on oils dissolved in n-hexane were described in the earlier paper [11]). Additionally, excitation and emission cords of feature are shifted to longer wavelengths for the second peak for oil dissolved in seawater in relation to the oil dissolved in n-hexane. Moreover, for the whole area of EEMs presented in Figure 6, in both cases of crude oil dissolved in $\mathrm{n}$-hexane and seawater, it is clearly visible that the range of ex- 


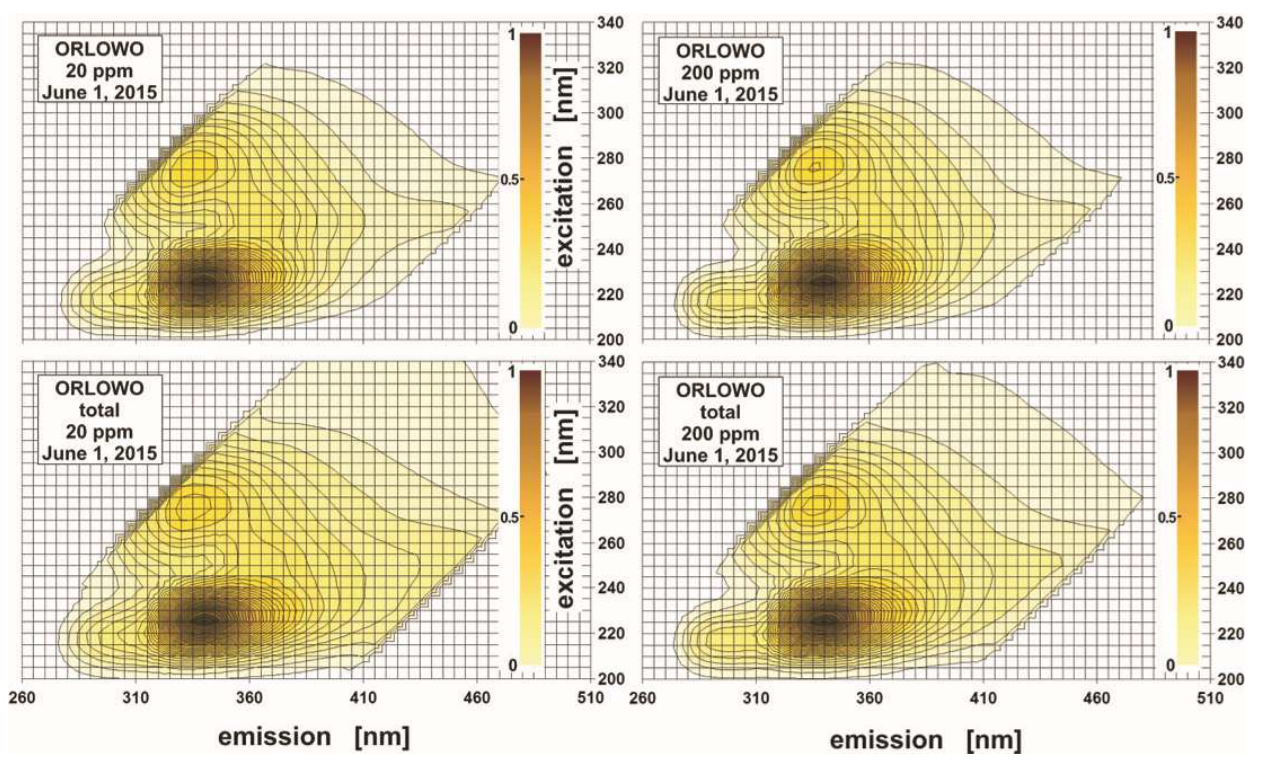

FIG. 5 Normalized EEMs of Petrobaltic crude oil dissolved in seawater from the ORLOWO station caused by only oil component (upper row) and by both oil components and seawater constituents (bottom row) for oil concentrations of $20 \mathrm{ppm}$ and $200 \mathrm{ppm}$.

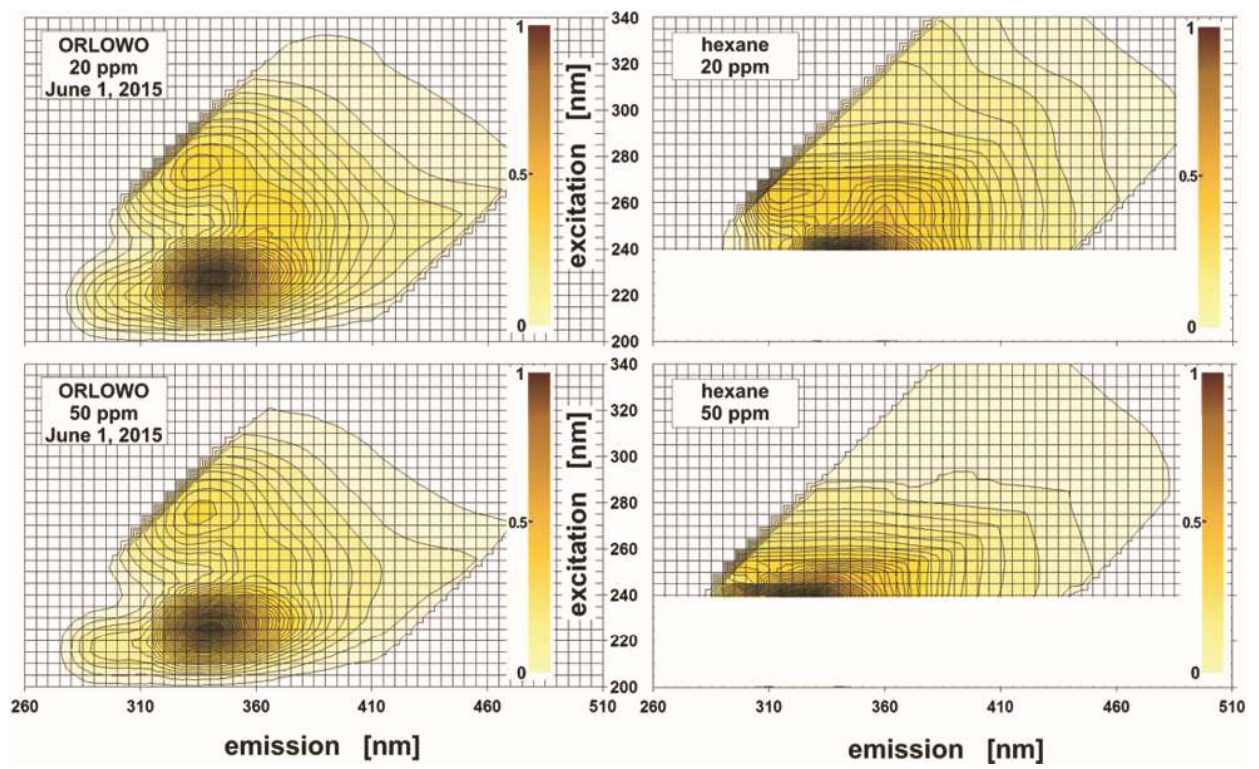

FIG. 6 Normalized EEM spectra of crude oil Petrobaltic: dissolved in seawater from the ORLOWO station (left) and dissolved in n-hexane [11] for two oil concentrations, 20 ppm and $50 \mathrm{ppm}$.

citation wavelength changes from $200 \mathrm{~nm}$ to $350 \mathrm{~nm}$ although the emission wavelength changes from $270 \mathrm{~nm}$ to $480 \mathrm{~nm}$, despite the EEMs of oil dissolved in n-hexane being slightly wider in both excitation and emission wavelengths than the EEMs of oil dissolved in n-hexane.

Additionally, when the natural seawater components are taken away (due to Formula (1)), the EEM spectrum matrix reveals the specific peaks for oil.

$$
w_{i j}^{a}=w_{i j}^{b}-w_{i j}^{c}
$$

$w_{i j}^{a}$ - element representing EEM for polluted seawater, when seawater components are taken away

$w_{i j}^{b}$ - element representing EEM for polluted seawater

$w_{i j}^{c}$ - element representing EEM for unpolluted seawater

The results indicate that the similarity degree of EEM matrices for seawater contaminated by oil in relation to the matrices for natural seawater without oil components always increases when the amount of oil increases. This means that in heavily-polluted seawater the fluorescence signatures of natural seawater components are non-detectable. The previouslymentioned similarity degree of EEMs is mathematically ex- 


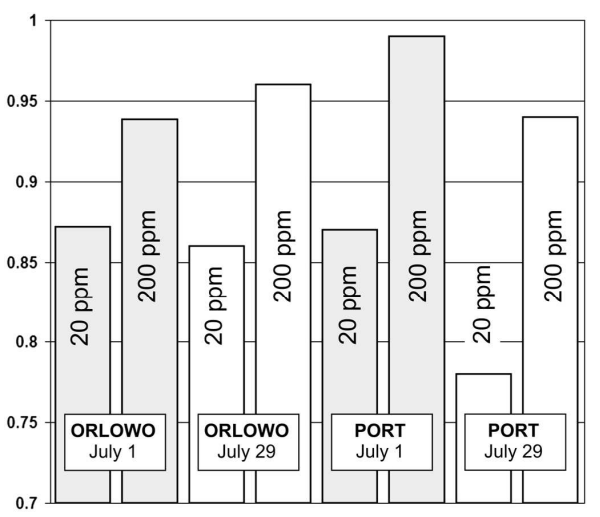

FIG. 7 Similarity $\left(\mathrm{s}_{a b}\right)$ between excitation-emission matrices for polluted water and polluted water after subtracting the fluorescence factor originating from natural components of the seawater.

pressed by Formula (2). In this formula, the indexes "ij" refer to relative columns and rows in matrix representing spectra "a" - artificially polluted water and spectra " $b$ " - for the same water after removing (due to Formula (1)) the factor originating from natural components, the quantities $\mathrm{w}_{i j}^{a}, \mathrm{w}_{i j}^{b}$ refer to normalised elements of EEMs matrices, respectively.

Those comparisons were performed after spectra normalization related to the maximum of fluorescence. The value of $\mathrm{s}_{a b}$ can vary from 0 (absolutely lack of similarity) to 1 (identical). Results of such comparisons for eight artificiallycontaminated samples of seawater are indicated in Figure 7. The similarity for highly-contaminated water is always greater than for slightly-contaminated water. This means that fluorescence signatures from natural components are shadowed by signatures originating from oil pollution.

$$
s_{a b}=1-\frac{\sum_{i j} a b s\left(w_{i j}^{a}-w_{i j}^{b}\right)}{\sum_{i j} w_{i j}^{a}+\sum_{i j} w_{i j}^{b}}
$$

\section{CONCLUSIONS}

Based on the described unique method of artificial contamination of seawater by an oil, it is possible to consider fluorescence features of the water-soluble part of oil. Obtained EEM spectra indicate difference between natural seawater and seawater contaminated by a small amount of oil. The results of fluorescence spectra (EEMs) for natural seawater and seawater polluted by oil-substances indicate that seawater fluorescence intensity increases after exposure to oil pollution (about 4 times at concentration $20 \mathrm{ppm}$ ) and causes the optical signatures of natural seawater components to be overlapped and become non-detectable. This phenomenon may reduce the accuracy of optical measurements of natural seawater components in the presence of oil contaminants even in smaller concentrations of oil than 20 ppm considered in the paper.

In the future activities are envisaged that laboratory measurements of fluorescence will cover spectra of different kind of oil such as: lubricate oil or fuels dissolved in different types of costal seawater or in different time in year. This will lead to improved classification of oil in different types water bodies i.e. harbour waters or near the outlet of storm waters collectors. It can be expected that the collected data will expand knowledge of the spectroscopic properties of oil pollutants in seawater and in the future may be used to construct an efficient optical sensor for oil detection and even type of oil identification directly in a sea environment.

\section{ACKNOWLEDGEMENTS}

This paper was partially supported by Gdynia Maritime University grant No. DS/411/2015 and No. 06/BMN/WM/2015.

\section{References}

[1] Z. A. Otremba, "Modelling of the light transfer in a water column polluted with oil suspension," J. Eur. Opt. Soc.-Rapid 8, 13067 (2013).

[2] U. Frank, "A review of fluorescence spectroscopic method for oil spill source identification," Toxilogical and Env. Chem. Reviews 2, 163-185 (1978).

[3] C. D. Geddes, and J. R. Lakowicz, Review in fluorescence 2005 (Springer, Heidelberg/Berlin, 2005).

[4] G. G. Guilbault, Practical fluorescence (CRC Press, Boca Raton, 1990).

[5] M. Fingas, The Basics of Oil Spill Cleanup (CRC Press, Boca Raton, 2013).

[6] M. Fingas, and C. Brown, "Review of oil spill remote sensors," in Proceedings to Seventh International Conference on Remote Sensing for Marine and Coastal Environments (Environmental Research Institute of Michigan (ERIM), Miami, 2002).

[7] T. A. Dolenko, V. V. Fadeev, I. V. Gerdova, S. A. Dolenko, and R. Reuter, "Fluorescence diagnostics of oil pollution in coastal marine waters by use of artificial neural networks," Appl. Optics 41 (24), 5155-5166 (2002).

[8] J. B. F. Lloyd, "Synchronized excitation of fluorescence emission spectra," Nature Phys. Sci. 231, 64-65 (1971).

[9] D. Patra, and A. K. Mishra, "Total synchronous fluorescence scan spectra of petroleum products," Anal. Bioanal. Chem. 373 (4)-(5), 304-309 (2002).

[10] L. Poryvkina, S. Babichenko, and 0. Davydova, "SFS characterisation of oil pollution in natural water," in Proceedings to Fifth International Conference on Remote Sensing for Marine and Coastal Environments, 520-524 (Michigan Tech Research Institute, San Diego, 1998).

[11] E. Baszanowska, and Z. Otremba, "Spectral signatures of fluorescence and light absorption to identify crude oils found in the marine environment," J. Eur. Opt. Soc.-Rapid 9, 14029 (2014).

[12] E. Baszanowska, 0. Zielinski, Z. Otremba, and H. Toczek, "Influence of oil-in-water emulsions on fluorescence properties as observed by excitation-emission spectra," J. Eur. Opt. Soc.-Rapid 8, 13069 (2013).

[13] A. Stelmaszewski, "Fluorescence method for determination of oil identity," Opt. Appl. 304 (3), 405-418 (2004).

[14] D. Patra, and A. K. Mishra, "Recent developments in multicomponent synchronous fluorescence scan analysis," Trend. Anal. Chem. 21 (12), 787-798 (2002). 
[15] M. Shaver, and L. B. McGown, "Fluorescence Studies of Complex Coal Liquid Samples Using the Lifetime Synchronous Spectrum (LiSS)," Appl. Spectrosc. 49 (6), 813-818 (1995).

[16] Paula G. Coble, "Characterization of marine and terrestrial DOM in seawater using excitation-emission matrix spectroscopy," Mar. Chem. 51 (4), 325-346 (1996).

[17] P. G. Coble, "Marine Optical Biogeochemistry: The Chemistry of ocean Color," Chem. Rev. 107 (2), 402-418 (2007).

[18] P. G. Coble, "Colored dissolved organic matter in seawater," in Subsea Optics and Imaging, J. Watson, and 0. Zielinski, eds., (1st Edition, Woodhead Publishing, Cambridge, 2013).

[19] V. Drozdowska, W. Freda, E. Baszanowska, K. Rudz, M. Darecki, J. Heldt, and H. Toczek, "Spectral properties of natural and oil polluted Baltic seawater - results of measurements and modelling," Eur. Phys. J.-Spec. Top. 222, 2157-2170 (2013).

[20] P. Kowalczuk, J. Ston-Egiert, W. J. Cooper, R. F. Whitehead, and $\mathrm{M}$, J. Durako, "Characterization of chromophoric dissolved organic matter (CDOM) in the Baltic Sea by excitation emission matrix fluorescence spectroscopy," Mar. Chem. 96 (3), 273-292 (2005).

[21] J. H. Christensen, A. B. Hansen, J. Mortensen, and 0. Andersen, "Characterization and Matching of Oil Samples Using Fluorescence Spectroscopy and Parallel Factor Analysis," Anal. Chem. 77 (7), 2210-2217 (2005).

[22] E. Baszanowska, Z. Otremba, H. Toczek, and P. Rohde, "Fluorescence spectra of oil after it contacts with aquatic environment," Journal of KONES Powertrain and Transport 20 (3), 29-34 (2013).
[23] Z. Otremba, E. Baszanowska, H. Toczek, P. Rohde., Spectrofluorometry applied to oil-in-water emulsion characterization, Journal of KONES Powertrain and Transport 18 (3), 317-321 (2011).

[24] M. Ostrowska, "Model dependences of the deactivation of phytoplankton pigment excitation energy on environmental conditions in the sea," Oceanologia 54 (4), 545-564 (2012).

[25] K. Rudz, H. Toczek, and M. Darecki, "Modelling the influence of oil content on optical properties of sea water in the Baltic Sea," J. Europ. Opt. Soc. Rap. Public. 8, 13063 (2013).

[26] W. Freda, "Comparison of the spectral-angular properties of light scattered in the Baltic Sea and oil emulsions," J. Eur. Opt. Soc.Rapid 9, 14017 (2014).

[27] S. P. Garaba, T. H. Badewien, A. Braun, A.-C. Schulz, and 0. Zielinski, "Using ocean colour remote sensing products to estimate turbidity at the Spiekeroog Wadden Sea time series station," J. Eur. Opt. Soc.-Rapid 9, 14020 (2014).

[28] Horiba Scientific, Operation manual (2011).

[29] J. Para, P. G. Coble, B. Charriere, M. Tedetti, C. Fontana, and R. Sempere, "Fluorescence and absorption properties of chromophoric dissolved organic matter (CDOM) in coastal surface waters of the north-western Mediterranean Sea," Biogeosciences 7 , 4083-4103 (2010). 